Pediat. Res. 1: 436-442 (1967)

$\begin{array}{ll}\begin{array}{l}\text { Cystic fibrosis of } \\ \text { the pancreas }\end{array} & \text { sodium } \\ \text { pancreas } & \text { parotid gland } \\ \text { saliva } & \text { ouabain }\end{array}$

\title{
A Sodium Transport Inhibitory Factor in the Saliva of Patients with Cystic Fibrosis of the Pancreas
}

\author{
J.A. Mangos ${ }^{[15]}$, N.R. MaSherry and P.J.Benke \\ Department of Pediatrics, University of Wisconsin Medical School, Madison, Wisconsin, USA
}

\begin{abstract}
Extract
The saliva of patients with cystic fibrosis of the pancreas (CFP) contains higher concentrations of sodium than the saliva of normal subjects. The hypothesis that the salivary electrolyte abnormality in CFP may be due to a sodium transport inhibitory factor (or factors) present in the saliva of these"patients was investigated. Such a factor would decrease sodium reabsorption in the salivary glands and cause increased sodium concentrations in the final saliva. Retrograde perfusion of the rat parotid gland was used to determine this factor. Retrograde perfusion with normal saline or saliva from normal children did not affect the rate of sodium reabsorption in the rat parotid gland. Retrograde perfusion with ouabain containing saline or saliva from patients with CFP resulted in a marked decrease of the rate of sodium reabsorption. It was concluded that saliva from patients with CFP contains a factor that causes inhibition of sodium transport in the rat parotid gland. The similarity of the effects of ouabain and saliva from patients with CFP led us to the investigation of the possibility of a common mode of action. It was demonstrated that the saliva of patients had no effect on the in vitro activity of membrane ATPase preparations obtained from beef parotid, human erythrocytes and rat kidneys. This indicates that the saliva of patients with CFP causes inhibition of sodium reabsorption in the rat parotid by an action other than inhibition of the activity of ATPase, an enzyme known to be involved in sodium transport across biological membranes.
\end{abstract}

\section{Speculation}

A factor that inhibits sodium reabsorption in the rat parotid gland has been demonstrated in the saliva of patients with CFP. The same factor may be causing the salivary electrolyte abnormality of GFP. If this is true, this factor should be present in the sweat of patients with GFP since the elctrolyte abnormality is maximally expressed in the sweat glands. It is hoped that study of this factor may lead us closer to the nature of the molecular defect of CFP.

Introduction

Cystic fibrosis of the pancreas (CFP) is an hereditary disorder affecting the exocrine glands of the patients [3]. Abnormalities of the physical character of mucus and of the composition of glycoproteins have been described in the products of different exocrine glands. Abnormalities of the electrolyte composition of sweat, mixed mouth saliva and parotid saliva are also constant features of the disease. Higher sodium and chlo- 
ride concentrations are found regularly in these excretory products [3]. It is difficult to visualize how these abnormalities can be the results of a single defect. It is difficult to suggest which of these abnormalities might be primary reflections of the underlying genetic defect and which are secondary.

We have approached this problem by studying the pathogenesis of the abnormal electrolyte composition of the saliva in patients with CFP. In the past, studies of this abnormality were limited because little was known about the basic mechanism and chemistry of salivary gland function. Recently, the introduction of micropuncture and microanalytical techniques in the studies of salivary gland function has resulted in significant advancement in the understanding of glandular secretion $[5,6,7,11]$. We have studied the mechanism of excretion of total solute, sodium and potassium in the saliva of the rat parotid gland $[5,6]$. We have demonstrated directly that the rat parotid secretes a plasma-like fluid in the acini-intercalated ducts [6]. This fluid then flows along the duct system of the gland and is modified by processes of reabsorption and secretion of electrolytes. Salivary hypotonicity is produced during passage of the fluid through the striated ducts where sodium reabsorption in excess of that of water takes place.

During the series of experiments described in this paper, we investigated the hypothesis that the salivary electrolyte abnormality of patients with CFP may be due to the presence of a sodium transport inhibitory factor (or factors) in the saliva of these patients. Such a factor would decrease sodium reabsorption in the duct system of the gland and permit increased sodium concentrations in the final saliva. The parotid gland of the rat was used as the experimental model for this study. Retrograde perfusion of the rat parotid with saliva from patients with CFP resulted in a marked inhibition of sodium reabsorption. Perfusion with saliva from healthy subjects had no effect on the sodium reabsorption. It was concluded that a sodium transport inhibitory factor is present in the saliva of patients with CFP. This factor may be responsible for the increased sodium concentrations in the saliva of these patients. In addition, we investigated the possibility that this effect could be due to an inhibition of the activity of the $\left(\mathrm{Na}^{+}+\mathrm{K}^{+}\right)$-dependent, ouabain-sensitive adenosinetriphosphatase (ATPase), an enzyme important in sodium transport. By using a preparation of ATPase in vitro, we could not demonstrate any effect from the saliva of patients with CFP on this enzyme.

\section{Materials and Methods}

\section{Patients and Control Subjects}

The patients with CFP were among those followed in the Cystic Fibrosis Clinic of the Medical Center of the University of Wisconsin, Madison, Wisconsin. They all had the symptoms and signs of the disease, and the diagnosis was confirmed by the increased sodium and chloride concentrations of the sweat collected following iontophoresis of the skin with pilocarpine. The control subjects were healthy children and young adults unrelated to those with CFP. The age, sex and sodium concentrations in the sweat and saliva of the patients and the healthy subjects are shown on table I.

\section{Saliva Collections}

Each subject was given chewing gum and was instructed to chew it for 3 minutes. At the end of this period, the chewing gum was removed and the saliva accumulating in the mouth for the following 3 minutes was discarded. Finally, saliva was collected for 3-5 minutes and was centrifuged at $3000 \times \mathrm{g}$ for 5 minutes.

Table I. Age, sex and sodium concentration in the saliva and sweat of the subjects from whom saliva was obtained

\begin{tabular}{|c|c|c|c|c|c|c|c|c|c|}
\hline & \multicolumn{4}{|c|}{ Control subjects } & & \multicolumn{4}{|c|}{ Patients with GFP } \\
\hline & $\begin{array}{l}\text { Age } \\
\text { in years }\end{array}$ & Sex & $\begin{array}{l}\text { Saliva }[\mathrm{Na}] \\
(\mathrm{mEq} / \mathrm{l})\end{array}$ & $\begin{array}{l}\text { Sweat }[\mathrm{Na}] \\
(\mathrm{mEq} / \mathrm{l})\end{array}$ & & $\begin{array}{l}\text { Age } \\
\text { in years }\end{array}$ & Sex & $\begin{array}{l}\text { Saliva }[\mathrm{Na}] \\
(\mathrm{mEq} / \mathrm{l})\end{array}$ & $\begin{array}{l}\text { Sweat }[\mathrm{Na}] \\
(\mathrm{mEq} / \mathrm{l})\end{array}$ \\
\hline 1. M.S. & 9 & $\mathrm{~m}$ & 12.5 & 21.6 & K.H. & 9 & $\mathrm{~m}$ & 20.5 & 123.2 \\
\hline 2. G.Z. & 14 & $\mathrm{~m}$ & 11.6 & 31.2 & W.S. & 14 & $\mathrm{~m}$ & 20.0 & 108.1 \\
\hline 3. T.L. & 15 & $\mathrm{~m}$ & 12.5 & 27.6 & J.V. & 16 & $\mathrm{~m}$ & 27.6 & 138.2 \\
\hline 4. D.G. & 14 & $\mathrm{~m}$ & 15.0 & 31.6 & D.F. & 15 & $\mathrm{~m}$ & 27.0 & 116.2 \\
\hline 5. J.S. & 9 & $f$ & 8.5 & 22.8 & M.S. & 9 & $f$ & 30.0 & 118.5 \\
\hline 6. R.L. & 10 & $f$ & 16.0 & 24.5 & K.T. & 10 & $f$ & 38.5 & 91.9 \\
\hline 7. P.A. & 13 & $f$ & 9.5 & 42.0 & D.W. & 13 & $f$ & 26.5 & 128.8 \\
\hline 8. K.D. & 20 & $f$ & 16.8 & 39.4 & D.A. & 22 & $f$ & 32.5 & 129.6 \\
\hline 9. J.T. & 27 & $f$ & 11.3 & 41.4 & B.Y. & 23 & $f$ & 28.5 & 132.5 \\
\hline
\end{tabular}

29 Pediat. Res., Vol. 1, No. 6 (1967) 
The clear supernatant was aspirated and used in the experiments described below.

\section{Solutions Used for Retrograde Perfusion}

All solutions used for retrograde perfusion were colored with a standard amount of the biological dye lissamine green $(1.0 \mathrm{mg} / \mathrm{ml})$. The various solutions were as follows: $1.0 .154 \mathrm{M} \mathrm{NaCl}$ in water (isotonic saline); 2. ouabain $10^{-3} \mathrm{M}$ in isotonic saline; 3. saliva from normal control subjects diluted $1: 4$ in isotonic saline; 4. saliva from patients with GFP diluted $1: 4$ in isotonic saline. The sodium and potassium concentrations of the $1: 4$ mixture of saliva and saline were between $118.0-124.0$ and $2.5-5.0 \mathrm{mEq} / 1$ respectively.

\section{Rat Parotid Gland Preparation}

Male albino rats of the Sprague-Dawley strain weighing $150-200 \mathrm{~g}$ were used in these experiments. Following anesthesia of the rat with sodium pentobarbital (sodium 5-ethyl-5-1-methylbutyl barbiturate), tracheostomy and cannulation of the left jugular vein were performed. The duct of the right parotid was dissected through a skin incision 1-2 $\mathrm{mm}$ posterior to the right corner of the mouth. A part of the parotid was exposed through a skin incision below the right ear and bathed in mineral oil. The solution used for retrograde perfusion was injected into the main duct by means of a fine polyethylene tube connected to a tuberculin syringe while the surface of the gland was observed under a dissecting microscope (magnification $\times 100$ ). The perfusion was stopped when the green solution entered the acini-intercalated duct region of the gland. By gentle pressure, the solution was kept at this level for 90 seconds. The pressure was released by cutting the tube at the appropriate length for saliva collection. The gland was then stimulated with pilocarpine $(0.1 \mathrm{mg} / 100 \mathrm{~g}$ of body weight $)$ injected intravenously into the rat. Salivary flow began immediately. The saliva collected in the first two minutes was approximately three times the volume of the duct system of the gland. This saliva was discarded. Serial collections of saliva were made for the following 20-30 minutes. The fluid was collected under mineral oil in tared polyethylene vessels. Following each experiment the gland was dissected and weighed.

\section{Analytical Methods}

The amount of the samples was measured gravimetrically. The salivary flow rate was expressed as $\mu \mathrm{l} / \mathrm{min} / \mathrm{g}$ of wet gland tissue by assuming that $1 \mathrm{mg}$ saliva equals $1 \mu 1$. Salivary sodium and potassium concentrations were measured by the use of the Instrumentation Laboratory Flame Photometer (Model 143).
6. Method for the study of the effects of saliva from patients with CFP on membrane and microsome ATPase activity in vitro

Beef parotid gland was used as a source of membrane ATPase. Heavy membrane fractions were prepared as described by Krnsolving [2]. Following separation of the heavy membranes, the supernatant was recentrifuged at $23,000 \times \mathrm{g}$ for 10 minutes. The sediment, containing mainly mitochondria, was discarded. The supernatant, containing the microsome fractions, was centrifuged at $97,000 \times \mathrm{g}$ for 120 minutes. The microsomes were collected from the bottom of the tube. Heavy membranes and microsomes were treated with $\mathrm{NaI}(2 \mathrm{M})$ for 30 minutes by an adaptation of the method of NAKaO [8]. This procedure destroys the Mg-dependent ATPase significantly more than the $\left(\mathrm{Na}^{+}+\mathrm{K}^{+}\right)$-dependent ATPase of membranes from human red cells and kidney. The suspensions containing heavy membrane fractions and microsomes were diluted to $0.6 \mathrm{M} \mathrm{NaI}$ and centrifuged as above. The separated fractions were washed five times with ethylene-diamine-tetraacetic acid (EDTA) $5 \mathrm{mmoles} / \mathrm{l}$. The enzyme-containing fractions were suspended in $0.25 \mathrm{M}$ sucrose solution and were stored at $-70^{\circ}$. The activity was stable for four weeks.

The reaction mixture for ATPase determination contained Imidazole $\mathrm{HCl} 60$ mmoles (pH 7.2), $\mathrm{MgCl}_{2}$ 3 mmoles, KGI 20 mmoles and NaCl 100 mmoles $/ 1$. A $40-80 \mu$ g portion of enzyme protein was added per ml. The saliva from patients with CFP was diluted $1: 1$ with water. To a $0.6 \mathrm{ml}$ aliquot of the reaction mixture, $0.3 \mathrm{ml}$ of the diluted saliva was added; these were incubated at $37^{\circ}$ for 15 minutes. Then, $0.1 \mathrm{ml}$ of a solution containing 20 mmoles of adenosine-triphosphate (ATP) was added. After 30 minutes of incubation at $37^{\circ}, 0.3 \mathrm{ml}$ of a $30 \%$ trichloracetic acid (TCA) solution was added. Inorganic phosphate was determined by the method of Hurst [1]. Protein was determined by the method of Lowry [4]. Ouabain-insensitive ATPase was defined as the activity occurring in the presence of $10^{-3} \mathrm{M}$ ouabain. The assays were run in duplicate and the results agreed within $5 \%$. TCA-inactivated reaction mixtures with and without saliva were used as blanks.

\section{Results}

1. The relation between the flow rate and the sodium concentration in the parotid saliva of ten rats, in which no retrograde perfusion was performed, is shown in figure 1. At low flow rates, the gland excreted saliva with decreased sodium concentrations. At progressively higher flow rates, a gradual increase in the sodium concentration of saliva was observed. Following retrograde 


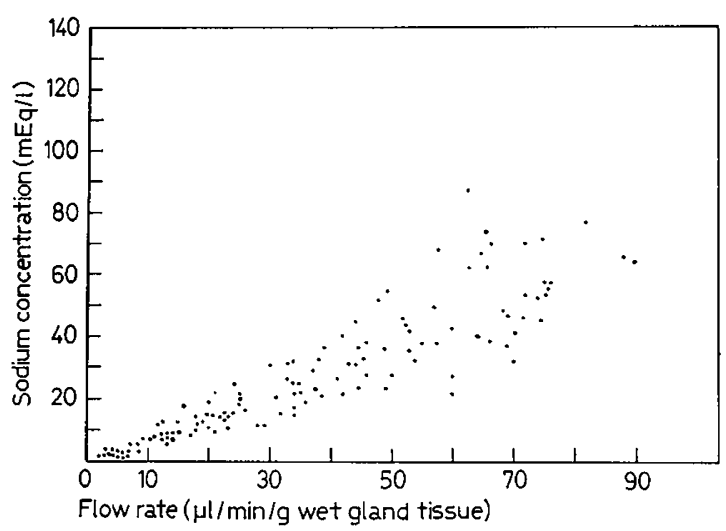

Fig. 1. The relation between sodium concentration and flow rate in the parotid saliva of 10 rats. These animals did not undergo retrograde perfusion.

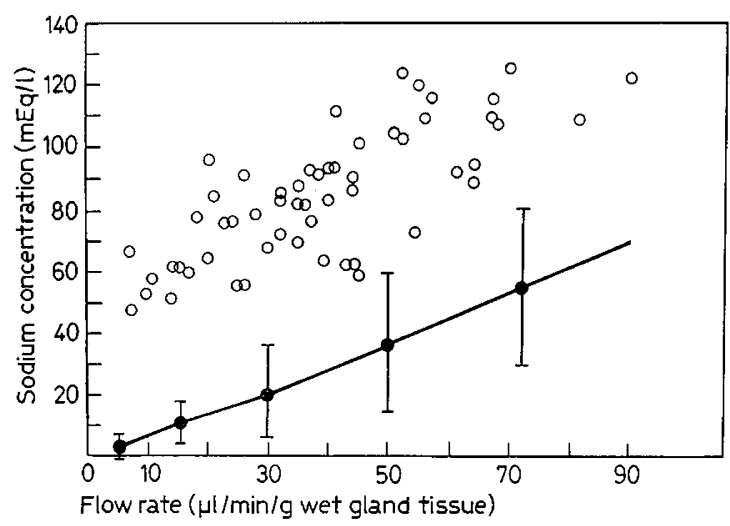

Fig. 3. The relation between sodium concentration and flow rate in the parotid saliva of 6 rats following retrograde perfusion of the glands with ouabain $\left(10^{-3} \mathrm{M}\right)$ in isotonic saline. Dark dots and vertical lines as in figure 2.

Fig. 5. The relation between sodium concentration and flow rate in the parotid saliva of 8 rats following retrograde perfusion of the glands with saliva from patients with CFP (one part) in isotonic saline (four parts). Dark dots and vertical lines as in figure 2.

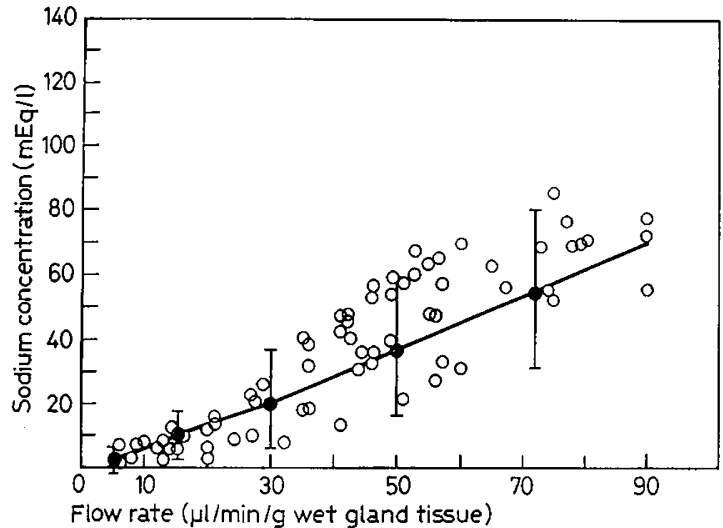

Fig. 2. The relation between sodium concentration and flow rate in the parotid saliva of 6 rats following retrograde perfusion of the glands with isotonic saline. The dark dots represent mean values and the vertical lines \pm 2 standard deviations of the data shown in figure 1 .

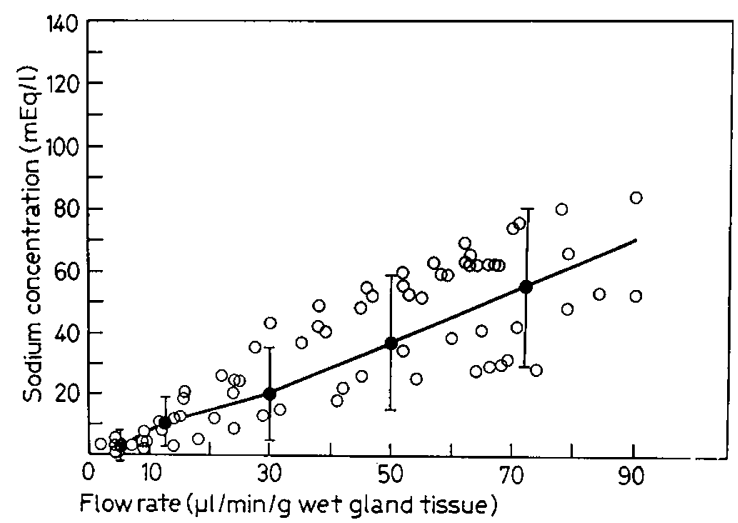

Fig.4. The relation between sodium concentration and flow rate in the parotid saliva of 8 rats following retrograde perfusion of the glands with saliva from normal subjects (one part) in isotonic saline (four parts). Dark dots and vertical lines as in figure 2 .

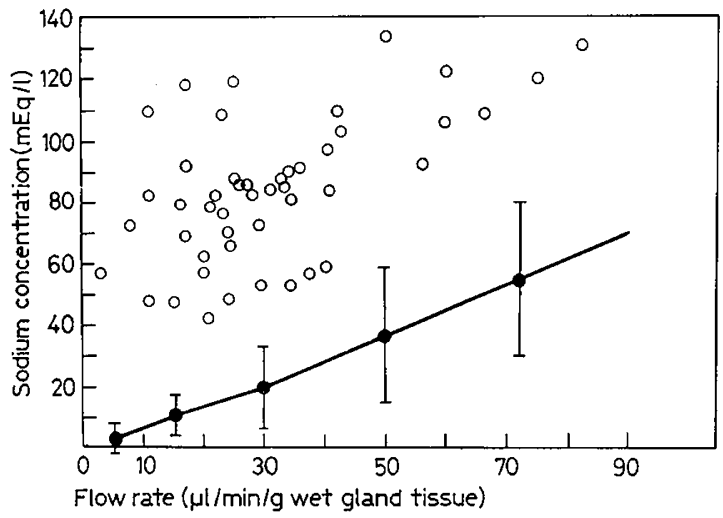




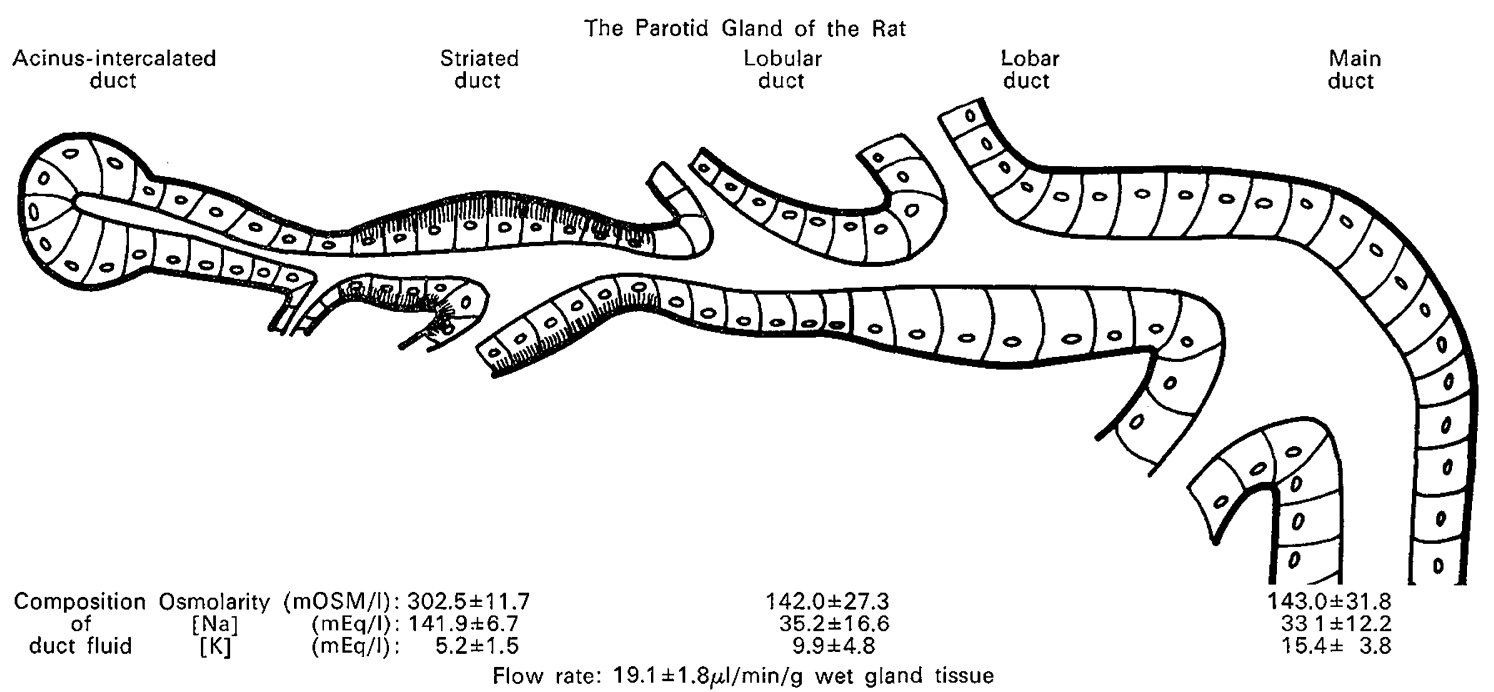

Fig.6. Diagram showing the structure of the duct system of the rat parotid and the changes in the composition of the duct fluid as it flows along the ducts of the pilocarpine-stimulated gland [6].

Table II. Effect of saliva from patients with CFP on the ATPase activity of heavy membranes and microsomes from beef parotid glands. (ATPase activity expressed as $\mu$ moles of inorganic $\mathrm{P}$ formed $/ \mathrm{h} / \mathrm{mg}$ protein)

\begin{tabular}{lllll}
\hline & Patient & $\begin{array}{l}\text { Reaction mixture } \\
\text { without ouabain } \\
10^{-3} \mathrm{M}\end{array}$ & $\begin{array}{l}\text { Reaction mixture } \\
\text { with GFP } \\
\text { saliva }\end{array}$ & $\begin{array}{l}\text { Reaction mixture } \\
\text { with ouabain } \\
10^{-3} \mathrm{M}\end{array}$ \\
\hline Heavy membrane & K.H. & 14.0 & 15.6 & 5.5 \\
& R.R. & 12.0 & 11.9 & 5.1 \\
Microsomes & G.S. & 10.4 & 12.0 & 4.9 \\
& K.H. & 38.7 & 43.1 & 23.1 \\
& R.R. & 34.1 & 35.3 & 24.1 \\
& G.S. & 30.0 & 33.7 & 23.1 \\
\hline
\end{tabular}

perfusion of the gland with normal saline (fig.2), the relation between salivary sodium concentration and flow rate did not change significantly. When the duct system of the gland was perfused with ouabain containing normal saline (fig. 3), a marked increase in the sodium concentration of saliva was observed at all flow rates.

2. Retrograde perfusion of the rat parotid with saliva from healthy children (fig. 4) had no significant effect on the relations between sodium concentration of saliva and flow rate. When the rat parotid was perfused with saliva from patients with CFP (fig. 5), a marked increase in the sodium concentration of saliva was observed at all flow rates.

3. As shown in table II, the saliva of patients with CFP had no effect either on the activity of the $\mathrm{Na}+\mathrm{K}$ activated, ouabain-sensitive ATPase of membrane, or on the microsomal fractions from beef parotid glands.
Discussion and Additional Results

This study demonstrates that saliva of patients with CFP contains a factor(s) that produces an abnormality of sodium excretion in the rat parotid when the saliva comes in contact with the wall of the duct system of the gland. This contact was accomplished by using a technique for retrograde perfusion of the rat parotid recently developed in our laboratory [5]. Following retrograde perfusion with saliva from patients, the rat parotid excreted saliva with increased sodium concentrations at all rates of salivary flow. This abnormality is similar to the well-known abnormality of sodium excretion in the mixed mouth saliva [9], parotid saliva [10], and sweat [3] of patients with CFP. The exact nature of this effect is not clear. However, if the present results are related to our recent micropuncture studies, a working hypothesis explaining the nature of the 
electrolyte abnormality of CFP may be formulated.

The duct system of the rat parotid is composed of three functionally different segments, acini-intercalated ducts, striated ducts, and excretory ducts (fig.6). By puncturing the duct system at different levels and analyzing the fluid samples thus obtained, we have been able to define the function of each duct segment [6]: a) the acini-intercalated ducts secrete a primary fluid with concentrations of sodium and potassium similar to that of plasma and osmolarity; b) the striated ducts produce salivary hypotonicity by active reabsorption of sodium in excess of water; c) the excretory ducts (lobular, lobar and main) convey the saliva to the mouth and secrete small quantities of potassium into the duct fluid. In addition, we have shown that the retrograde perfusion of the duct system of the gland with 0.154 $\mathrm{M} \mathrm{NaCl}$ solution does not affect the mechanism of production of salivary hypotonicity by sodium reabsorption [5]. Thus, it became feasible to introduce different transport inhibitors into the duct system of the gland and apply them on the luminal side of the wall. From the above studies, it is apparent that in order to inhibit sodium reabsorption, the inhibitor must reach the striated ducts.

In these experiments, the effects of retrograde perfusion of the rat parotid with different solutions were expressed as changes in the sodium concentration of the final saliva following stimulation of the gland with pilocarpine. Since in the duct system of the rat parotid only the striated ducts reabsorb sodium from the duct fluid, we have accepted the changes in the concentration of sodium in the final saliva as representative of changes in the sodium reabsorption in the striated ducts. An alternative explanation is possible. Following retrograde perfusion of the gland with a transport inhibitor, the composition of the primary fluid produced in the acini-intercalated ducts is altered. We have excluded this possibility by puncturing intercalated ducts following retrograde perfusion of the rat parotid with ouabain and sodium cyanide and demonstrated that the primary fluid had osmolarity and concentrations of sodium and potassium similar to that of plasma. Therefore, we feel that the changes in the sodium concentration of the final saliva observed in these experiments represent changes in the reabsorptive capacity of the striated ducts of the rat parotid.

Neither isotonic saline nor a mixture of saline and saliva from normal children had any effect on sodium reabsorption. In contrast, saline containing ouabain and saliva from patients with GFP had a profound inhibitory effect on sodium reabsorption in the striated ducts as indicated by the marked increase in concentrations of sodium in saliva at all flow rates. That the striated ducts are the site of this effect was also demonstrated as follows: in three experiments, the level of retrograde perfusion with ouabain containing saline or the mixture of saline and saliva from patients with CFP was limited from the main duct to the lobular ducts; there was no inhibition of sodium reabsorption and the sodium concentrations of the final saliva were identical with that obtained from control rats. Thus, we concluded that the saliva of patients with GFP contains a factor that causes partial inhibition of sodium reabsorption when applied on the luminal side of the striated ducts of the rat parotid gland. The magnitude of this effect is similar to that produced by ouabain.

The similarity of the effects of ouabain and saliva from patients on the sodium reabsorption led us to consider the possibility of a common mode of action. Ouabain inhibits the activity of the $\left(\mathrm{Na}^{+}+\mathrm{K}^{+}\right)$dependent ATPase of transporting biological membranes. In our in vitro experiments, we could not demonstrate an effect of saliva from patients on the ATPase activity of membrane and microsomal fractions from beef parotid glands. In addition, saliva from patients had no effect on the ATPase activity of membranes from human erythrocytes and rat kidney [12]. We feel that these results may be considered an indication that the factor in the saliva of patients causes inhibition of sodium reabsorption by an action other than inhibition of ATPase activity. Additional studies demonstrated that this factor was destroyed by heating saliva to $100^{\circ}$ or freezing-thawing of the saliva. Storage of the saliva at $4^{\circ}$ for 24 hours caused a decrease in the activity by $20-40 \%$. The possibility that this activity in the saliva of patients is related to an increased calcium concentration was also investigated. In three experiments, calcium was added to saliva from a normal child at concentrations of 2, 6 and $12 \mathrm{mEq} / \mathrm{l}$. Retrograde perfusion of the rat parotid with this saliva had no effect on sodium reabsorption.

Differences in sodium concentration between the saliva of patients and that of control subjects may also be excluded as a cause of this effect since the differences were eliminated by the dilution of saliva with isotonic saline.

Our system permits quantitative measurements of the activity of the sodium transport inhibitory factor present in the saliva of patients with CFP. In previous studies, we demonstrated that practically no water reabsorption takes place in the rat parotid gland at salivary flow rates higher than $30 \mu \mathrm{l} / \mathrm{min} / \mathrm{g}$ of wet gland tissue and that the sodium concentration of the primary fluid secreted by the acini-intercalated ducts is $141.9 \pm$ $6.7 \mathrm{mEq} / 1[5,6]$. The rate of sodium reabsorption $\left(\mathrm{R}_{\mathrm{Na}}\right)$ by the gland can be calculated by subtracting the rate of sodium excretion in the final saliva $\left(\mathrm{FE}_{\mathrm{Na}}\right)$ from the rate of sodium secretion in the primary fluid $\left(\mathrm{PS}_{\mathrm{Na}}\right)$ : $\mathrm{R}_{\mathrm{Na}}=\left(\mathrm{PS}_{\mathrm{Na}}\right)-\left(\mathrm{FE}_{\mathrm{Na}}\right)$ 
The rate of sodium excretion in the final saliva $\left(\mathrm{FE}_{\mathrm{Na}}\right)$ can be calculated as follows:

$\left(\mathrm{FE}_{\mathrm{Na}}\right)=[\mathrm{Na}]_{\mathrm{FS}} \times \mathrm{FR}$

where $[\mathrm{Na}]_{\mathrm{FS}}$ is the sodium concentration in the final saliva and FR the salivary flow rate.

The rate of sodium secretion in the primary fluid $\left(\mathrm{PS}_{\mathrm{Na}}\right)$ can be calculated as follows:

$\left(\mathrm{PS}_{\mathrm{Na}}\right)=[\mathrm{Na}]_{\mathrm{PF}} \times \mathrm{FR}$

where $[\mathrm{Na}]_{\mathrm{PF}}$ is the sodium concentration of the primary fluid secreted by the acini-intercalated ducts of the gland. By applying these equations to the indivual measurements obtained during this study, the rate of sodium reabsorption in the rat parotid during the different phases of the present experiments was calculated. As shown on table III, retrograde perfusion of the gland with isotonic saline or saliva from normal subjects had no effect on the rate of sodium reabsorption. Retrograde perfusion with ouabain or saliva from patients with CFP caused a marked decrease in the rate of sodium reabsorption.

Table III. Rate of sodium reabsorption by the rat parotid gland $(\mu \mathrm{Eq} / \mathrm{min} / \mathrm{g}$ wet gland tissue)

1. No retrograde perfusion

6.01

2. Retrograde perfusion with isotonic saline

3. Retrograde perfusion with ouabain $\left(10^{-3} \mathrm{M}\right)$ in isotonic saline

$2.44(\mathrm{p}<0.001)$

4. Retrograde perfusion with saliva from normal subjects in isotonic saline

5. Retrograde perfusion with saliva from patients with CFP in isotonic saline

$1.84(\mathrm{p}<0.001)$

\section{Conclusion}

It has been demonstrated that saliva from patients with CFP contains a factor that inhibits sodium reabsorption in the rat parotid gland. This factor may be the one that causes the increased salinity of the saliva of patients with CFP by an analogous inhibition of sodium reabsorption in their salivary glands. We hope that further study of this factor may lead us closer to the nature of the molecular defect in CFP.
References and Notes

1. Hurst, R.O.: The determination of nucleotide phosphorus with a stannous chloride-hydrazine sulfate reagent. Canad.J. Biochem. 42: 287 (1964).

2. Kinsolving, G. R.; Post, R. L. and Beaver, D. L. : Sodium plus potassium transport adenosine triphosphatase activity in kidney. J. cell. comp. Physiol. 62: 85 (1963).

3. Lobeck, G. C.: Cystic fibrosis; in Metabolic basis of inherited diseases (ed. Stanbury, J. B.; WyngaARDEN, J. B. and FREDRICKSON,D. S.), pp.1300-1317 (McGraw-Hill, New York 1965).

4. Lowry, O.H.; Rosebrough, N.J.; Farr, A.L. and Randall, R.J.: Protein measurement with the Folin phenol reagent. J. biol. Chem. 193: 265 (1951).

5. Mangos, J.A. and Braun, G.: Excretion of total solute sodium and potassium in the saliva of the rat parotid gland. Pflügers Arch.ges. Physiol. 290: 184 (1966).

6. Mangos, J.A.; Braun, G. and Hamann, K.F.: Micropuncture study of sodium and potassium excretion in the rat parotid saliva.Pflügers Arch. ges. Physiol. 291: 99 (1966).

7. Martinez, J.R.; HolzGreve, H. and Frick, A.: Micropuncture study of submaxillary glands of adult rats. Pflügers Arch.ges. Physiol. 290: 124 (1966).

8. NAKaO, T.; NAGANO, K. ; Adadin, K. and NAKaO, M.: Separation of two adenosine triphosphatases from erythrocyte membrane. Biochem. Biophys. Res. Comm. 13: 444 (1963).

9. Prader, A. und Gautrer, E.: Die Na- und KKonzentration im gemischten Speichel II. Erhöhte Werte bei der Pankreasfibrose. Helv. paediat. Acta 10: 56 (1955).

10. Saggers, B.A.; Lawson, D.; Stern, J. and EdGson, A. C. : Rapid method for the detection of cystic fibrosis of the pancreas in children. Arch.Dis. Childh. 42: 187 (1967).

11. Young, J.A. and Schoeged, E.: Micropuncture investigation of sodium and potassium excretion in rat submaxillary saliva. Pflügers Arch. ges. Physiol. 291: 85 (1966).

12. Unpublished observations.

13. Supported by Grant AM-06365 from the N.I.A. M.D. and by the National Cystic Fibrosis Research Foundation.

14. The authors wish to thank Dr. Charles C. Lobegk for encouragement and valuable criticism of this work.

15. Mangos, J.A., M.D., Assistant Professor, Department of Pediatrics, University of Wisconsin Medical School, Madison, Wis. 53706 (USA). 